\title{
Effect of surface curvature on oxidation of a MCrAlY coating
}

DOI:

10.1016/j.corsci.2019.108256

\section{Document Version}

Accepted author manuscript

Link to publication record in Manchester Research Explorer

\section{Citation for published version (APA):}

Chen, Y., Zhao, X., \& Xiao, P. (2020). Effect of surface curvature on oxidation of a MCrAlY coating. Corrosion Science, 163, 1-9. [108256]. https://doi.org/10.1016/j.corsci.2019.108256

\section{Published in:}

Corrosion Science

\section{Citing this paper}

Please note that where the full-text provided on Manchester Research Explorer is the Author Accepted Manuscript or Proof version this may differ from the final Published version. If citing, it is advised that you check and use the publisher's definitive version.

\section{General rights}

Copyright and moral rights for the publications made accessible in the Research Explorer are retained by the authors and/or other copyright owners and it is a condition of accessing publications that users recognise and abide by the legal requirements associated with these rights.

\section{Takedown policy}

If you believe that this document breaches copyright please refer to the University of Manchester's Takedown Procedures [http://man.ac.uk/04Y6Bo] or contact uml.scholarlycommunications@manchester.ac.uk providing relevant details, so we can investigate your claim.

\section{OPEN ACCESS}




\section{Journal Pre-proof}

Effect of surface curvature on oxidation of a MCrAlY coating

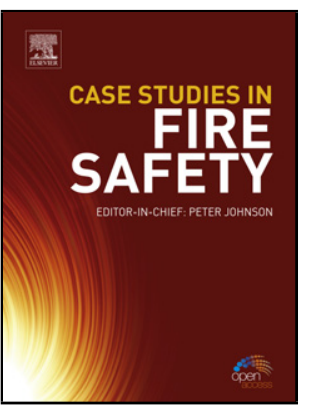

PII:

S0010-938X(19)30996-5

DOI:

https://doi.org/10.1016/j.corsci.2019.108256

Reference:

CS 108256

To appear in:

Corrosion Science

Received Date:

14 May 2019

Revised Date:

19 August 2019

Accepted Date:

3 October 2019

Please cite this article as: Chen Y, Zhao X, Xiao P, Effect of surface curvature on oxidation of a MCrAlY coating, Corrosion Science (2019), doi: https://doi.org/10.1016/j.corsci.2019.108256

This is a PDF file of an article that has undergone enhancements after acceptance, such as the addition of a cover page and metadata, and formatting for readability, but it is not yet the definitive version of record. This version will undergo additional copyediting, typesetting and review before it is published in its final form, but we are providing this version to give early visibility of the article. Please note that, during the production process, errors may be discovered which could affect the content, and all legal disclaimers that apply to the journal pertain.

C 2019 Published by Elsevier. 


\section{Effect of surface curvature on oxidation of a MCrAlY coating}

Ying Chen ${ }^{\mathrm{a}}$, Xiaofeng Zhao ${ }^{\mathrm{b}}$ and Ping Xiao ${ }^{\mathrm{a*}}$

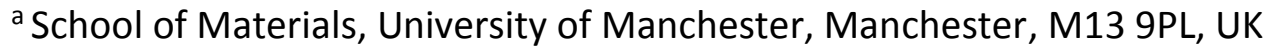

${ }^{b}$ Shanghai Key Laboratory of Advanced High-Temperature Materials and Precision

Forming, Shanghai Jiao Tong University, Shanghai, 200240, PR China

*Corresponding author: Ping Xiao (p.xiao@manchester.ac.uk).

Graphical abstract

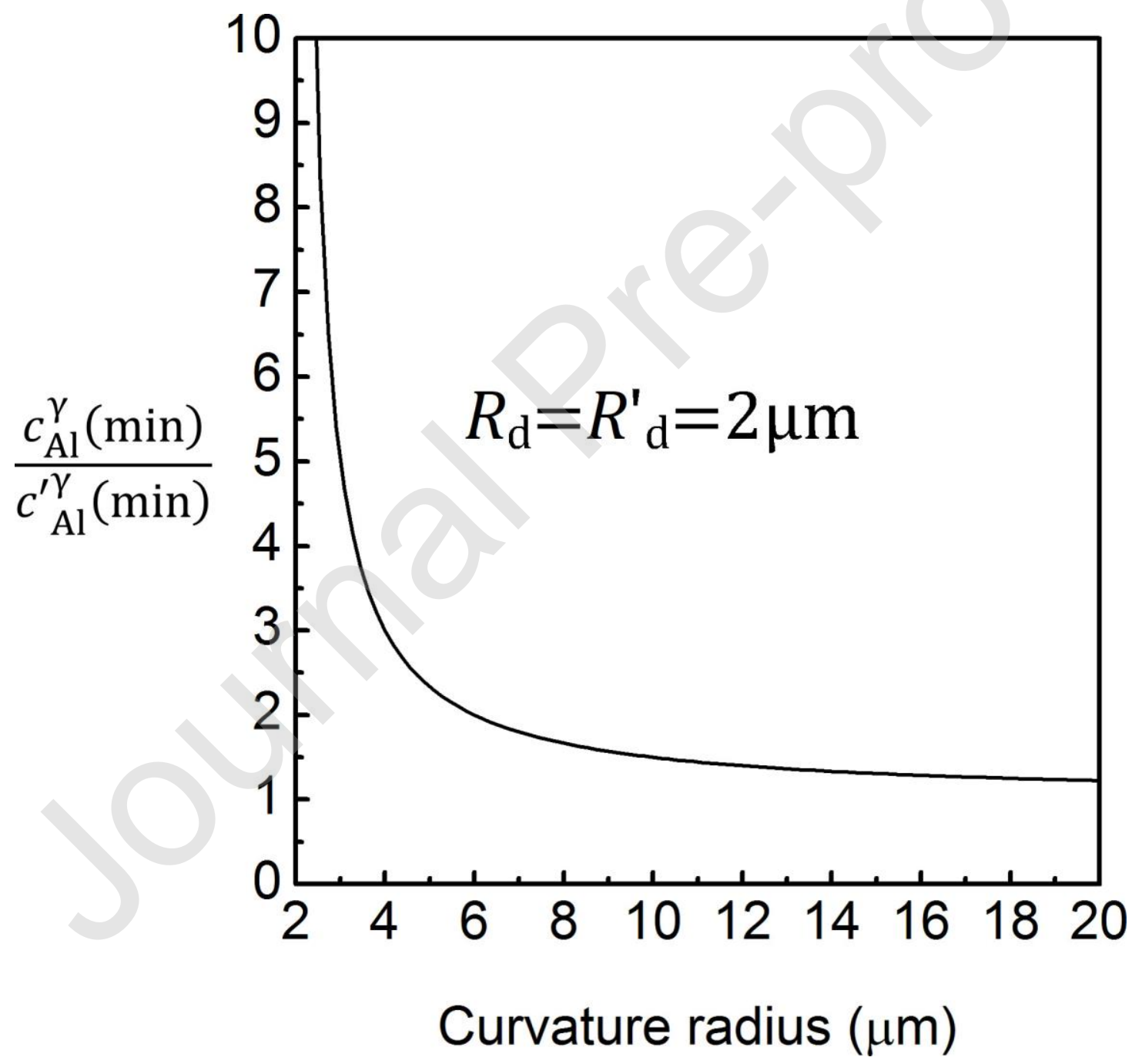




\section{Highlights}

1. The HVOF MCrAlY coating show site specific oxidation

2. The oxides in convex regions consist of outer spinel and inner $\alpha-\mathrm{Al}_{2} \mathrm{O}_{3}$

3. The oxides in concave regions are comprised of exclusive $\alpha-\mathrm{Al}_{2} \mathrm{O}_{3}$

4. Diffusion models are developed to explain the curvature dependent oxidation

\section{Abstract}

The oxidation behaviour of a high velocity oxygen fuel (HVOF) sprayed MCrAlY coating at $1150{ }^{\circ} \mathrm{C}$ is studied. The rough coating surface shows site-specific oxidation: the oxides in the convex regions show duplex microstructure, consisting of outer $(\mathrm{Ni}, \mathrm{Co})(\mathrm{Cr}, \mathrm{Al})_{2} \mathrm{O}_{4}$ and inner $\alpha-\mathrm{Al}_{2} \mathrm{O}_{3}$; the oxides in the concave regions, however, show single-layered microstructure comprised of exclusive $\alpha-\mathrm{Al}_{2} \mathrm{O}_{3}$. Diffusional analysis predicts that in order to form an exclusive $\alpha-\mathrm{Al}_{2} \mathrm{O}_{3}$ scale the minimum Al concentration in the $\gamma$-phase matrix in the convex regions must be higher than that in the concave regions. The study provides new insight into oxidation of MCrAlY coatings.

Keywords: MCrAlY Coating; Oxidation; Curvature

\section{Introduction}

Metallic overlay coatings based on MCrAlY ( $\mathrm{M}=\mathrm{Ni}$ and/or $\mathrm{Co}$ ) alloys are widely used in gas-turbine engines to protect the superalloy components against high temperature oxidation and hot corrosion [1-4]. The protection of these coatings relies on their capabilities to form and maintain a slow-growing and thermodynamically stable $\alpha-\mathrm{Al}_{2} \mathrm{O}_{3}$ scale on the surface during exposure to high temperatures. The development of the external protective $\alpha-\mathrm{Al}_{2} \mathrm{O}_{3}$ scale becomes 
even more crucial when the MCrAlY coatings are used as bond coats in thermal barrier coating (TBC) systems. This is because $\alpha-\mathrm{Al}_{2} \mathrm{O}_{3}$ is not only an excellent barrier to oxygen diffusion, but also thermodynamically compatible with the thermal insulating ceramic topcoat (typically made of 7-8 wt\% yttria stabilised zirconia (YSZ)) [5], which is critical to the maintenance of the interfacial adhesion in the TBC systems.

It has been well known that the oxidation behaviour of MCrAlY coatings depends on a number of factors, including but not limited to the chemical composition of the coatings (e.g. the $\mathrm{Al}$ and $\mathrm{Y}$ contents [6-11]), the oxidation conditions (e.g. temperatures and oxygen partial pressures $[8,12-14])$ and the microstructure of the coatings (e.g. the grain size of individual phases [15-17]). Apart from the aspects mentioned above, it has also been shown that surface roughness of the MCrAlY coatings may affect the microstructure and composition of the thermally grown oxides (TGOs) $[8,18,19]$, although this effect has not been sufficiently studied or understood yet. Czech et al. [18] and Gil et al. [19] have compared the oxidation behaviours of MCrAlY coatings with rough surface and polished surface. They have found that spinels (e.g. $\mathrm{NiCr}_{2} \mathrm{O}_{4}$ and $\mathrm{CoCr}_{2} \mathrm{O}_{4}$ ) and/or $\mathrm{Cr}_{2} \mathrm{O}_{3}$ form in accompany with $\alpha-\mathrm{Al}_{2} \mathrm{O}_{3}$ on the rough coating surface, whereas only an exclusive $\alpha-\mathrm{Al}_{2} \mathrm{O}_{3}$ scale is identified on the polished coating surface. Furthermore, Gil et al. have reported that there is a correlation between spinel formation and the local surface curvature, with spinels predominantly growing in the convex regions of the coating surface [19]. The formation of the brittle, fast-growing transient oxides is disruptive and undesirable as they are less protective than $\alpha-\mathrm{Al}_{2} \mathrm{O}_{3}$ and are detrimental to the interfacial adhesion, especially in the case where an YSZ TBC is present. Nevertheless, a theoretical understanding of the surface curvature dependent oxidation behaviour is still unavailable. On the other hand, MCrAlY coatings are mostly produced by thermal spraying (e.g. air plasma spraying (APS), low pressure plasma spraying (LPPS) and high velocity oxygen fuel (HVOF) spraying) for industrial applications. A prevailing feature of these thermally sprayed MCrAlY coatings is the rough surface. Therefore, a thorough mechanistic understanding of the effect of surface curvature on oxidation behaviour of MCrAlY coatings is also of practical importance.

The objective of this work is to provide detailed experimental characterisation and theoretical interpretation of the surface curvature dependent oxidation behaviour of a HVOF MCrAIY coating. The microstructure and composition of the TGOs in the peak and valley regions of the rough coating surface are compared and characterised in great details. Following the experimental characterisation, the Al diffusion during selective oxidation of $\mathrm{Al}$ in both convex and concave surface areas are modelled. The implications of our modelling results are also discussed and correlated to the observations in this work. The study gives new insights into oxidation of MCrAlY coatings. 


\section{Materials and Methods}

A NiCoCrAlY (Ni-23Co-17Cr-12.5Al-0.6Y (wt.\%)) overlay coating was thermally sprayed on one side of a Hastelloy ${ }^{\oplus} X$ superalloy plate $\left(50 \times 30 \times 5 \mathrm{~mm}^{3}\right)$ using HVOF. The microstructure, phase content and chemical composition of the coating have been described in detail elsewhere $[16,20,21]$. But briefly, the coating is dense, homogeneous and exhibits a two-phase microstructure (Al-lean $\gamma$-phase matrix and Al-rich $\beta$-phase precipitates). The average thickness of the coating is $215 \mu \mathrm{m}$, varying between $\sim 200$ and $\sim 230 \mu \mathrm{m}$ from place to place due to the extensive surface roughness formed during the spraying process. The coated superalloy plate was cut into square-shaped samples $\left(8 \times 8 \mathrm{~mm}^{2}\right)$ using a SiC abrasive cutting blade in a precision cut-off machine (Accutom 10, Struers) for the following oxidation experiments.

Oxidation was performed in a $\mathrm{CM}^{\mathrm{TM}}$ automatic furnace in laboratory air. The samples were placed in the centre of the hot zone and isothermally oxidised at $1150^{\circ} \mathrm{C}$ for 5 hours. The furnace had a thermocouple fitted in the centre of the chamber to monitor the temperatures around the samples and synchronised the temperature data to the control program, which constantly adjusted the input power to meet the temperature setting.

After oxidation, the TGOs were cross-sectioned and analysed using a focused ion beam-scanning electron microscope (FIB-SEM) dual beam microscope (Helios NanoLab 660, FEI). The use of the FIB-SEM dual beam system allowed detailed site-specific analysis of the TGO cross-sections (e.g. the TGOs in the peak and valley regions) without introducing any mechanical damage. To study the microstructure and composition of the TGOs in greater details, cross-sectional thin lamellae of the TGOs were prepared by FIB and then analysed using a scanning transmission electron microscope (STEM, Titan G2, FEI) fitted with a Cs probe corrector and ChemiSTEM ${ }^{\text {TM }}$ technology (X-FEG and Super-X energy dispersive X-ray spectroscopy (EDS) with four windowless silicon drift detectors). The STEM was mainly operated in high-angle annular dark field (HAADF) imaging mode to reveal atomic number contrast and facilitate chemical analysis. The STEM samples were obtained by FIB milling through the TGOs in the regions of interest. The lamellae were then extracted and welded to a copper grid using a combination of an Omniprobe AutoProbe ${ }^{\mathrm{TM}}$ and a gas injection system fitted in the FIB-SEM system, followed by thinning to an electron transparent thickness $(<100 \mathrm{~nm}$ ). More details about STEM sample preparation could be found elsewhere [22]. To complement STEM characterisation, the thin TGO cross-sectional lamellae were further analysed using transmission Kikuchi diffraction (TKD) in an extreme high-resolution SEM (Magellan 400 XHRSEM, FEI) to map the crystallographic phases of the grains across the entire TGO scales. Compared with conventional electron backscattered diffraction, the thin lamellae 
used in TKD release the residual stress of the samples and the transmission geometry used in TKD significantly reduces the interaction volume between the electrons and the sample, and therefore a higher spatial resolution is achieved [23].

\section{Results}

\subsection{Microstructure and composition of the TGOs in convex surface regions}

Fig. 1 shows the cross-sectional TGO microstructure revealed by FIB milling in two convex surface regions after oxidation at $1150{ }^{\circ} \mathrm{C}$ for 5 hours. Most parts of the TGOs are essentially duplex, as suggested by the variation in the contrast through the TGO thickness. Fig. 2a-g present a HAADF-STEM image and corresponding X-ray maps of the TGO scale in a convex surface region. It is clearly seen that the TGO consists of a thin, outer $\mathrm{Ni} / \mathrm{Co} / \mathrm{Cr}$-rich oxide layer ( $300 \mathrm{~nm}$ thick) and an inner Al-rich oxide layer (1.32 $\mu \mathrm{m}$ thick) in contact with the underlying metal. TKD phase-contrast maps acquired from two different parts of the TGO scale (Fig. $2 \mathrm{~h}$ and i) show that the outer $\mathrm{Ni} / \mathrm{Co} / \mathrm{Cr}$-rich oxide layer has a spinel structure with equiaxed grains and the inner Al-rich oxide layer has a corundum structure with columnar grains. The combination of the STEM-EDS and TKD analysis suggests that the outer layer of the TGO scale is $(\mathrm{Ni}, \mathrm{Co})(\mathrm{Cr}, \mathrm{Al})_{2} \mathrm{O}_{4}$ and the inner layer of the TGO scale is $\alpha-\mathrm{Al}_{2} \mathrm{O}_{3}$. A string of intermittent pores is seen at the spinel/ $\alpha-\mathrm{Al}_{2} \mathrm{O}_{3}$ interface (Fig. 2a), which is probably attributed to the volumetric shrinkage associated with the solid-state reactions between oxides (e.g. $\mathrm{NiO}$ and $\alpha-\mathrm{Al}_{2} \mathrm{O}_{3}$ during spinel formation). Apart from the spinel and $\alpha-\mathrm{Al}_{2} \mathrm{O}_{3}$, cubic yttrium aluminium garnet ( $\mathrm{YAG}, \mathrm{Y}_{3} \mathrm{Al}_{5} \mathrm{O}_{12}$ ) precipitates are also identified in the TGO scale (Fig. 2h). The formation of these $\mathrm{Y}_{3} \mathrm{Al}_{5} \mathrm{O}_{12}$ inclusions is associated with the oxidation of yttrium doped in the coating and the subsequent solid-state reaction between yttria and $\alpha-\mathrm{Al}_{2} \mathrm{O}_{3}$. The interface between the TGO scale and the underlying coating is intact, without any presence of cracking or separation. Due to Al depletion induced by oxidation, the $\beta$-phase near the TGO/coating interface decomposes to the $\gamma$-phase, leading to the formation of a subsurface $\beta$ phase dissolution layer (a single $\gamma$-phase layer) in contact with the TGO.

\subsection{Microstructure and composition of the TGOs in concave surface regions}

Fig. 3 shows the cross-sectional TGO microstructure revealed by FIB milling in two concave surface regions after oxidation at $1150^{\circ} \mathrm{C}$ for 5 hours. Unlike the duplex structure of the TGOs in the convex surface regions, the TGOs in the concave surface regions show a single-layered structure, as suggested by the uniform contrast through the TGO thickness. Fig. 4a-g presents a HAADF-STEM image and corresponding $\mathrm{X}$-ray maps of the TGO scale in a concave surface region. The $\mathrm{Ni} / \mathrm{Co} / \mathrm{Cr}$-rich spinel layer found in the TGO in the convex surface region is not seen. Instead, only an Al-rich oxide layer (1.3 $\mu \mathrm{m}$ thick) and patchy $\mathrm{Y}$-rich oxide inclusions 
are identified in the TGO. TKD phase-contrast maps of the TGO scale (Fig. $4 \mathrm{~h}$ and $\mathrm{i}$ ) show that the Al-rich oxide layer is $\alpha-\mathrm{Al}_{2} \mathrm{O}_{3}$ with columnar grains. The thickness and microstructure of the $\alpha-\mathrm{Al}_{2} \mathrm{O}_{3}$ layers in the concave surface regions are close to those of the $\alpha-\mathrm{Al}_{2} \mathrm{O}_{3}$ layers in the convex surface regions. Similar to the observations in the convex surface regions, the TGO in the concave surface regions are also in contact with a subsurface $\beta$-phase dissolution layer due to Al depletion and subsequent $\beta$ to $\gamma$ phase transformation near the TGO/coating interface.

\subsection{Microstructure and composition of the TGOs at the initial stage of oxidation}

In principle, the spinel on MCrAlY coatings could form in two different ways. On one hand, the spinel could form at the very early stage of oxidation where the base metal elements ( $\mathrm{Ni}, \mathrm{Co}$ and $\mathrm{Cr}$ ) are oxidised together with $\mathrm{Al}$ or in preference over $\mathrm{Al}$. On the other hand, formation of the spinel could also occur after the establishment of a continuous $\alpha-\mathrm{Al}_{2} \mathrm{O}_{3}$ scale but the depletion of $\mathrm{Al}$ in the subsurface area reaches an extent that the subsequent diffusion flux of $A l$ towards the interface could not maintain the growth of exclusive $\alpha-\mathrm{Al}_{2} \mathrm{O}_{3}$. At this stage, it is unclear that the spinel seen in the convex surface areas (Figs. 1 and2) forms at which stage. To clarify this issue, the as-deposited HVOF coating was oxidised at $1150{ }^{\circ} \mathrm{C}$ for 5 minutes and the microstructure of the TGO was then examined in detail. Fig. 5 shows a representative cross-sectional HAADF-STEM image of the TGO in a convex surface region after oxidation at $1150^{\circ} \mathrm{C}$ for 5 minutes and corresponding diffraction analysis (as the TGO is extremely thin ( $300 \mathrm{~nm}$ ), SEM is less useful for microstructural and chemical analysis). The TEM analysis confirms that the TGO is exclusive $\alpha-\mathrm{Al}_{2} \mathrm{O}_{3}$ with a few YAG inclusions, which is in agreement with the previous observations made on the same HVOF coating [16]. Therefore, it must conclude that the spinel forms after a continuous $\alpha-\mathrm{Al}_{2} \mathrm{O}_{3}$ scale is established (between 5 mins and 5 hours).

\section{Discussion}

The findings in this work show that the microstructure and composition of the TGO on the HVOF NiCoCrAlY coating depend on the roughness induced surface microcurvature. The TGO in the peak region shows duplex microstructure, comprising an outer $(\mathrm{Ni}, \mathrm{Co})(\mathrm{Cr}, \mathrm{Al})_{2} \mathrm{O}_{4}$ spinel layer and an inner $\alpha-\mathrm{Al}_{2} \mathrm{O}_{3}$ layer. The TGO in the valley region, however, shows a single-layered microstructure with exclusive $\alpha-\mathrm{Al}_{2} \mathrm{O}_{3}$ grains. The formation of the spinel in the convex surface regions occurs after the establishment of an exclusive $\alpha-\mathrm{Al}_{2} \mathrm{O}_{3}$ scale, which is associated with the depletion of $\mathrm{Al}$ and the subsequent inadequate diffusion flux of $\mathrm{Al}$ to maintain the growth of exclusive $\alpha-\mathrm{Al}_{2} \mathrm{O}_{3}$. Indeed, the growth of a spinel layer on top of a continuous $\alpha-\mathrm{Al}_{2} \mathrm{O}_{3}$ scale has been reported in the literature [24-26] and a possible mechanism for this phenomenon is that $\mathrm{Ni}, \mathrm{Co}$ and $\mathrm{Cr}$ diffuse through the $\alpha-\mathrm{Al}_{2} \mathrm{O}_{3}$ scale along the high- 
angle grain boundaries in response to the low Al concentration at the TGO/metal interface[25].

The observations in this accelerated oxidation study, combined with the work of Gil et al. [19] at lower temperatures, in essence, highlights that the surface curvature dependent oxidation behaviour is a common phenomenon for thermally sprayed MCrAlY coatings oxidised at temperatures between $900-1150{ }^{\circ} \mathrm{C}$. To interpret the dependence of oxidation behaviour on the surface curvature, two models are proposed to represent the selective oxidation of $\mathrm{Al}$ in the convex and concave surface regions, respectively. Based on these two models, diffusional analyses are performed to establish the relationship between the surface curvature and the minimum concentration of $\mathrm{Al}$ in the metal to form an exclusive external $\alpha-\mathrm{Al}_{2} \mathrm{O}_{3}$ scale. The models and diffusional analyses will be explored below.

\subsection{Modelling and analysis of Al diffusion during selective oxidation of Al in the convex surface regions}

To facilitate our modelling and diffusional analysis, the metal and TGO in the convex coating surface regions are represented by a solid sphere and a spherical shell attached to the surface of the sphere, respectively (Fig. 6). Specifically, a NiCoCrAlY alloy sphere of radius $R$ is considered. The alloy contains Al-rich $\beta$-phase precipitates of an $\mathrm{Al}$ concentration $c_{\mathrm{Al}}^{\beta}$ in thermodynamic equilibrium with a $\gamma$ phase matrix of an $\mathrm{Al}$ concentration $c_{\mathrm{Al}}^{\gamma}\left(c_{\mathrm{Al}}^{\beta}>c_{\mathrm{Al}}^{\gamma}\right)$. The concentrations are in mole fractions. It is assumed that the NiCoCrAlY sphere oxidises to form an exclusive $\alpha$ $\mathrm{Al}_{2} \mathrm{O}_{3}$ scale on the surface of the sphere, together with a subsurface $\beta$-depleted zone (a single $\gamma$-phase layer) of thickness $R_{\mathrm{d}}\left(R_{\mathrm{d}}<\mathrm{R}\right)$ in contact with the $\alpha-\mathrm{Al}_{2} \mathrm{O}_{3}$ scale. The condition that $R_{\mathrm{d}}<R$ also suggests that the model is applicable to the scenario where the diffusion length of $\mathrm{Al}$ is smaller than the radius of curvature (which is the case for the NiCoCrAlY coating studied in this work). To further simplify our analysis, it is assumed that the interface is static (the displacement of the $\alpha$ $\mathrm{Al}_{2} \mathrm{O}_{3} / \gamma$-phase interface due to consumption of $\mathrm{Al}$ during oxidation is disregarded). The errors of this stationary $\alpha-\mathrm{Al}_{2} \mathrm{O}_{3} / \gamma$-phase interface treatment are negligible in the case that the growth rate of $\alpha-\mathrm{Al}_{2} \mathrm{O}_{3}$ is low and the corresponding $\mathrm{Al}$ consumption is relatively small [27]. It should be mentioned that the convex and concave regions on the NiCoCrAlY coating surface are alternated, which may result in variation in lateral Al concentrations and provoke Al diffusion in lateral directions. This effect is not considered in the model.

The concentration profile of $\mathrm{Al}, c_{\mathrm{Al}}(r)$, through the single $\gamma$-phase layer of the $\beta$ dissolution zone is obtained by solving Fick's second law in spherical coordinates [28] 


$$
\frac{\partial c_{\mathrm{Al}}(r)}{\partial t}=D_{\mathrm{Al}}^{\gamma}\left[\frac{\partial^{2} c_{\mathrm{Al}}(r)}{\partial r^{2}}+\frac{2}{r} \frac{\partial c_{\mathrm{Al}}(r)}{\partial r}\right]
$$

The boundary conditions are given by

$$
\begin{gathered}
R-R_{\mathrm{d}} \leq r<R \\
c_{\mathrm{Al}}(r)=c_{\mathrm{Al}}^{\mathrm{i}} \text { at } r=R \text { for } t>0 \\
c_{\mathrm{Al}}(r)=c_{\mathrm{Al}}^{\gamma} \text { at } r=R-R_{\mathrm{d}} \text { for } t \geq 0
\end{gathered}
$$

Where $r=R$ corresponds to the $\alpha-\mathrm{Al}_{2} \mathrm{O}_{3} / \gamma$-phase interface and $r=R-R_{\mathrm{d}}$ corresponds to the interface between the single $\gamma$-phase layer and the two-phase bulk alloy. $D_{\mathrm{Al}}^{\gamma}$ is the diffusion coefficient of $\mathrm{Al}$ in the $\gamma$-phase and assumed to be a constant and $t$ is oxidation time.

If we make a substitution $u=r c_{\mathrm{Al}}(r)$, Eq (1) becomes

$$
\frac{\partial u}{\partial t}=D_{\mathrm{Al}}^{\gamma} \frac{\partial^{2} u}{\partial r^{2}}
$$

By comparing to the solutions given by Carter et al. [27] and Gesmundo et al. [29] , the solution for $u$ is

$$
u=\left[\left(R-R_{\mathrm{d}}\right) c_{\mathrm{Al}}^{\gamma}-R c_{\mathrm{Al}}^{\mathrm{i}}\right] \frac{\operatorname{erf}\left(\frac{R-r}{2 \sqrt{D_{\mathrm{Al}}^{\gamma} t}}\right)}{\operatorname{erf}\left(\frac{R_{\mathrm{d}}}{2 \sqrt{D_{\mathrm{Al}}^{\gamma} t}}\right)}+R c_{\mathrm{Al}}^{\mathrm{i}}
$$

Therefore, $c_{\mathrm{Al}}(r)$ is given by

$$
c_{\mathrm{Al}}(r)=\frac{\left(R-R_{\mathrm{d}}\right) c_{\mathrm{Al}}^{\gamma}}{r} \frac{\operatorname{erf}\left(\frac{R-r}{2 \sqrt{D_{\mathrm{Al}}^{\gamma} t}}\right)}{\operatorname{erf}\left(\frac{R_{\mathrm{d}}}{2 \sqrt{D_{\mathrm{Al}}^{\gamma} t}}\right)}+\frac{R c_{\mathrm{Al}}^{\mathrm{i}}}{r}\left[1-\frac{\operatorname{erf}\left(\frac{R-r}{2 \sqrt{D_{\mathrm{Al}}^{\gamma} t}}\right)}{\operatorname{erf}\left(\frac{R_{\mathrm{d}}}{2 \sqrt{D_{\mathrm{Al}}^{\gamma} t}}\right)}\right]
$$


According to Fick's first law, the Al flux towards the TGO/metal interface, $J_{\mathrm{Al}}^{\mathrm{i}}$, is given by

$$
J_{\mathrm{Al}}^{\mathrm{i}}=-\left.\frac{D_{\mathrm{Al}}^{\gamma}}{V_{\mathrm{m}}^{\gamma}} \frac{\mathrm{d}\left[c_{\mathrm{Al}}(r)\right]}{\mathrm{d} r}\right|_{r=R}
$$

where $V_{\mathrm{m}}^{\gamma}$ is the molar volume of the $\gamma$-phase. Differentiating Eq (4) with respect to $r=R$ and substituting the solution to $\mathrm{Eq}(5)$ gives

$$
J_{\mathrm{Al}}^{\mathrm{i}}=\frac{1}{V_{\mathrm{m}}^{\gamma}} \sqrt{\frac{D_{\mathrm{Al}}^{\gamma}}{\pi t}} \frac{\left(R-R_{\mathrm{d}}\right)}{R} \frac{c_{\mathrm{Al}}^{\gamma}}{\operatorname{erf}\left(\frac{R_{\mathrm{d}}}{2 \sqrt{D_{\mathrm{Al}}^{\gamma} t}}\right)}-\frac{D_{\mathrm{Al}}^{\gamma}}{V_{\mathrm{m}}^{\gamma}} c_{\mathrm{Al}}^{\mathrm{i}}\left(\frac{1}{\operatorname{erf}\left(\frac{R_{\mathrm{d}}}{2 \sqrt{D_{\mathrm{Al}}^{\gamma} t}}\right) \sqrt{\pi D_{\mathrm{Al}}^{\gamma} t}}-\frac{1}{R}\right)
$$

As $\frac{1}{\operatorname{erf}\left(\frac{R_{\mathrm{d}}}{2 \sqrt{D_{\mathrm{Al}}^{\gamma}}}\right) \sqrt{\pi D_{\mathrm{Al}}^{\gamma} t}}-\frac{1}{R}>0$ (see Appendix for the determination of this

relationship), the maximum Al flux towards the TGO/metal interface, $J_{\mathrm{Al}}^{\mathrm{i}}$ (max), occurs if $c_{\mathrm{Al}}^{\mathrm{i}}=0$ (In reality, $c_{\mathrm{Al}}^{\mathrm{i}}$ is dynamic and must be above 0 (ranging from virtually zero to the Al concentration in the $\gamma$-matrix, depending on the growth kinetics of the $\alpha-\mathrm{Al}_{2} \mathrm{O}_{3}$ scale $\left.[30,31]\right)$ in order to thermodynamically equilibrate with the TGO. The consideration here is only a mathematical approximation which represents the extreme scenario which gives rise to $J_{\mathrm{Al}}^{\mathrm{i}}(\max )$ when $c_{\mathrm{Al}}^{\mathrm{i}}$ approaches 0 , which will be in turn used to determine the minimum Al concentration in the $\gamma$-phase matrix for maintaining an exclusive $\alpha-\mathrm{Al}_{2} \mathrm{O}_{3}$ scale, as derived below). Therefore

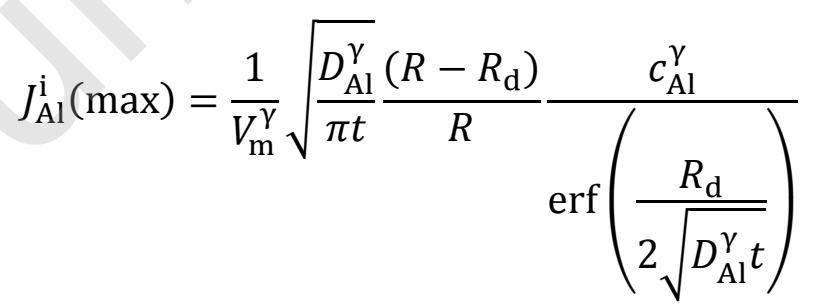

On the other hand, the instantaneous Al flux diffusing away from the interface, $J_{\mathrm{Al}(\mathrm{ox})}^{\mathrm{i}}$, for growth of the $\alpha-\mathrm{Al}_{2} \mathrm{O}_{3}$ scale is given by 


$$
J_{\mathrm{Al}(\mathrm{ox})}^{\mathrm{i}}=\frac{2}{V_{\mathrm{m}}^{\alpha-\mathrm{Al}_{2} \mathrm{O}_{3}}} \frac{\mathrm{d} h_{\alpha-\mathrm{Al}_{2} \mathrm{O}_{3}}}{\mathrm{~d} t}
$$

Where $h_{\alpha-\mathrm{Al}_{2} \mathrm{O}_{3}}$ and $V_{\mathrm{m}}^{\alpha-\mathrm{Al}_{2} \mathrm{O}_{3}}$ are the thickness and molar volume of the $\alpha-\mathrm{Al}_{2} \mathrm{O}_{3}$ scale.

According to Wagner's criterion [32], in order to maintain an exclusive $\alpha-\mathrm{Al}_{2} \mathrm{O}_{3}$ scale on the surface of the NiCoCrAlY alloy sphere $J_{\mathrm{Al}}^{\mathrm{i}}$ (max) must be equal to or greater than $J_{\mathrm{Al}(\mathrm{ox})}^{\mathrm{i}}$, which gives

$$
\frac{1}{V_{\mathrm{m}}^{\gamma}} \sqrt{\frac{D_{\mathrm{Al}}^{\gamma}}{\pi t}} \frac{\left(R-R_{\mathrm{d}}\right) c_{\mathrm{Al}}^{\gamma}}{R\left[\operatorname{erf}\left(\frac{R_{\mathrm{d}}}{2 \sqrt{D_{\mathrm{Al}}^{\gamma} t}}\right)\right]} \geq \frac{2}{V_{\mathrm{m}}^{\alpha-\mathrm{Al}_{2} \mathrm{O}_{3}}} \frac{\mathrm{d} h_{\alpha-\mathrm{Al}_{2} \mathrm{O}_{3}}}{\mathrm{~d} t}
$$

Reorganise Eq (9)

$$
c_{\mathrm{Al}}^{\gamma} \geq \frac{2 V_{\mathrm{m}}^{\gamma}}{V_{\mathrm{m}}^{\alpha-\mathrm{Al}_{2} \mathrm{O}_{3}}} \sqrt{\frac{\pi t}{D_{\mathrm{Al}}^{\gamma}}} \frac{R}{\left(R-R_{\mathrm{d}}\right)}\left[\operatorname{erf}\left(\frac{R_{\mathrm{d}}}{2 \sqrt{D_{\mathrm{Al}}^{\gamma} t}}\right)\right] \frac{\mathrm{d} h_{\alpha-\mathrm{Al}_{2} \mathrm{O}_{3}}}{\mathrm{~d} t}
$$

As a result, after reorganisation, the minimum Al concentration in the $\gamma$-phase matrix, $c_{\mathrm{Al}}^{\gamma}(\mathrm{min})$, to allow the formation of an exclusive $\alpha-\mathrm{Al}_{2} \mathrm{O}_{3}$ scale is given by

$$
c_{\mathrm{Al}}^{\gamma}(\min )=\frac{2 V_{\mathrm{m}}^{\gamma}}{V_{\mathrm{m}}^{\alpha-\mathrm{Al}_{2} \mathrm{O}_{3}}} \sqrt{\frac{\pi t}{D_{\mathrm{Al}}^{\gamma}}} \frac{R}{\left(R-R_{\mathrm{d}}\right)}\left[\operatorname{erf}\left(\frac{R_{\mathrm{d}}}{2 \sqrt{D_{\mathrm{Al}}^{\gamma} t}}\right)\right] \frac{\mathrm{d} h_{\alpha-\mathrm{Al}_{2} \mathrm{O}_{3}}}{\mathrm{~d} t}
$$

\subsection{Modelling and analysis of Al diffusion during selective oxidation of Al in the concave surface regions}

Following the methodology used in Section 4.1, the metal and the TGO in the concave surface region are modelled as a hollow sphere and a spherical shell attached to the inner surface of the sphere (Fig. 7), respectively. Specifically, a twophase $(\beta+\gamma)$, hollow NiCoCrAlY sphere with an inner radius of $R$ is considered. The compositional description of the individual phase of the NiCoCrAlY alloy is the same 
as that in Section 4.1. It is assumed that during oxidation an exclusive $\alpha-\mathrm{Al}_{2} \mathrm{O}_{3}$ scale forms on the inner surface of the hollow sphere and a subsurface $\beta$-depleted zone (a single $\gamma$-phase layer) of thickness $R_{\mathrm{d}}^{\prime}\left(R_{\mathrm{d}}^{\prime}<R\right)$ forms in accompany with the $\mathrm{Al}$ depletion. It is also assumed that the TGO growth rate is the same as that on the surface of the solid sphere considered in Section 4.1 (This assumption is partially supported by the almost identical thickness of the $\alpha-\mathrm{Al}_{2} \mathrm{O}_{3}$ scales observed on the convex and concave coating surface shown in Figs. 2 and 4). The $\alpha-\mathrm{Al}_{2} \mathrm{O}_{3} / \gamma$-phase interface is taken to be immobile with respect to time. Similar to the model in Section 4.1, the model considered here is applicable to the scenario where the diffusion length of $\mathrm{Al}$ is smaller than the radius of curvature and the diffusion of $\mathrm{Al}$ in lateral directions between the alternative convex and convex areas is not considered.

The boundary conditions for Fick's second law (Eqs (1)) are given by

$$
\begin{gathered}
R<r \leq R+R^{\prime}{ }_{\mathrm{d}} \\
c^{\prime}{ }_{\mathrm{Al}}(r)=c_{\mathrm{Al}}^{\mathrm{i}} \text { at } r=R \text { for } t>0 \\
c^{\prime}{ }_{\mathrm{Al}}(r)=c_{\mathrm{Al}}^{\gamma} \text { at } r=R+R^{\prime}{ }_{\mathrm{d}} \text { for } t \geq 0
\end{gathered}
$$

where $c^{\prime}{ }_{\mathrm{Al}}(r)$ is the concentration profile of Al through the single $\gamma$-phase layer of the $\beta$-phase dissolution zone; $r=R$ corresponds to the $\alpha-\mathrm{Al}_{2} \mathrm{O}_{3} / \gamma$-phase interface and $r=R+R_{\mathrm{d}}^{\prime}$ corresponds to the interface between the single $\gamma$-phase layer and the two-phase bulk alloy.

$c^{\prime}{ }_{\mathrm{Al}}(r)$ is solved as

$$
c^{\prime}{ }_{\mathrm{Al}}(r)=\frac{\left(R+R_{\mathrm{d}}^{\prime}\right) c_{\mathrm{Al}}^{\gamma}}{r} \frac{\operatorname{erf}\left(\frac{r-R}{2 \sqrt{D_{\mathrm{Al}}^{\gamma} t}}\right)}{\operatorname{erf}\left(\frac{R_{\mathrm{d}}^{\prime}}{2 \sqrt{D_{\mathrm{Al}}^{\gamma} t}}\right)}+\frac{R c_{\mathrm{Al}}^{\mathrm{i}}}{r}\left[1-\frac{\operatorname{erf}\left(\frac{r-R}{2 \sqrt{D_{\mathrm{Al}}^{\gamma} t}}\right)}{\operatorname{erf}\left(\frac{R_{\mathrm{d}}^{\prime}}{2 \sqrt{D_{\mathrm{Al}}^{\gamma} t}}\right)}\right]
$$

The Al flux at the TGO/metal interface, $J_{\mathrm{Al}}^{\mathrm{i}}$, is given by

$$
J_{\mathrm{Al}}^{\prime \mathrm{i}}=-\left.\frac{D_{\mathrm{Al}}^{\gamma}}{V_{\mathrm{m}}^{\gamma}} \frac{\mathrm{d}\left[c^{\prime}{ }_{\mathrm{Al}}(r)\right]}{\mathrm{d} r}\right|_{r=R}
$$


Differentiating Eq (12) with respect to $r=R$ and substituting the solution to Eq (13) gives

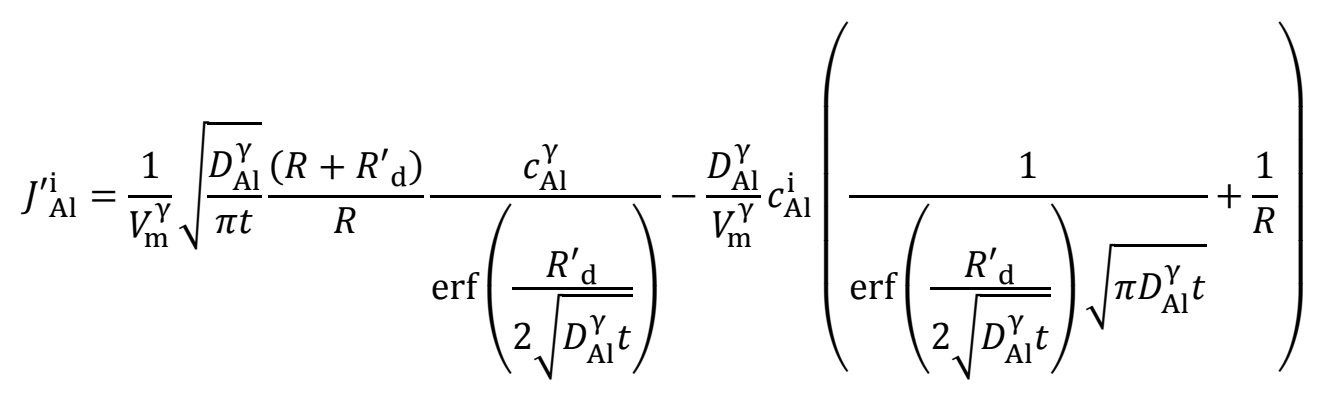

As $\frac{1}{\operatorname{erf}\left(\frac{R^{\prime} \mathrm{d}}{2 \sqrt{D_{\mathrm{Al}}^{\gamma}}}\right) \sqrt{\pi D_{\mathrm{Al}}^{\gamma} t}}+\frac{1}{R}>0$, the maximum Al flux towards the TGO/metal interface, $J_{\mathrm{Al}}^{\mathrm{i}}(\max )$, occurs if $c_{\mathrm{Al}}^{\mathrm{i}}=0$. Therefore

$$
J_{\mathrm{Al}}^{\mathrm{i}}(\max )=\frac{1}{V_{\mathrm{m}}^{\gamma}} \sqrt{\frac{D_{\mathrm{Al}}^{\gamma}}{\pi t}} \frac{\left(R+R_{\mathrm{d}}^{\prime}\right)}{R} \frac{c_{\mathrm{Al}}^{\gamma}}{\operatorname{erf}\left(\frac{R_{\mathrm{d}}^{\prime}}{2 \sqrt{D_{\mathrm{Al}}^{\gamma} t}}\right)}
$$

The instantaneous Al flux diffusing away from the interface, $J_{\mathrm{Al}(\mathrm{ox})}^{\mathrm{i}}$, for growth of the $\alpha-\mathrm{Al}_{2} \mathrm{O}_{3}$ scale is still given by Eq ( 8 ) for the same $\alpha-\mathrm{Al}_{2} \mathrm{O}_{3}$ growth rate. To form an exclusive $\alpha-\mathrm{Al}_{2} \mathrm{O}_{3}$ scale on the inner surface of the hollow alloy sphere, $J^{\prime \mathrm{i}}$ (max) must be equal to or greater than $J_{\mathrm{Al}(\mathrm{ox})}^{\mathrm{i}}$, which gives

$$
\frac{1}{V_{\mathrm{m}}^{\gamma}} \sqrt{\frac{D_{\mathrm{Al}}^{\gamma}}{\pi t}} \frac{\left(R+R_{\mathrm{d}}^{\prime}\right) c_{\mathrm{Al}}^{\gamma}}{R\left[\operatorname{erf}\left(\frac{R_{\mathrm{d}}^{\prime}}{2 \sqrt{D_{\mathrm{Al}}^{\gamma} t}}\right)\right]} \geq \frac{2}{V_{\mathrm{m}}^{\alpha-\mathrm{Al}_{2} \mathrm{O}_{3}}} \frac{\mathrm{d} h_{\alpha-\mathrm{Al}_{2} \mathrm{O}_{3}}}{\mathrm{~d} t}
$$

Reorganise Eq (16)

$$
c_{\mathrm{Al}}^{\gamma} \geq \frac{2 V_{\mathrm{m}}^{\gamma}}{V_{\mathrm{m}}^{\alpha-\mathrm{Al}_{2} \mathrm{O}_{3}}} \sqrt{\frac{\pi t}{D_{\mathrm{Al}}^{\gamma}}} \frac{R}{\left(R+R_{\mathrm{d}}^{\prime}\right)}\left[\operatorname{erf}\left(\frac{R_{\mathrm{d}}^{\prime}}{2 \sqrt{D_{\mathrm{Al}}^{\gamma} t}}\right)\right] \frac{\mathrm{d} h_{\alpha-\mathrm{Al}_{2} \mathrm{O}_{3}}}{\mathrm{~d} t}
$$


Therefore, after rearrangement, the minimum Al concentration in the $\gamma$-phase matrix, $c^{\prime \gamma}{ }_{A l}(\mathrm{~min})$, to maintain the growth of an exclusive $\alpha-\mathrm{Al}_{2} \mathrm{O}_{3}$ scale is given by

$$
c_{\mathrm{Al}}^{\prime \gamma}(\min )=\frac{2 V_{\mathrm{m}}^{\gamma}}{V_{\mathrm{m}}^{\alpha-\mathrm{Al}_{2} \mathrm{O}_{3}}} \sqrt{\frac{\pi t}{D_{\mathrm{Al}}^{\gamma}}} \frac{R}{\left(R+R_{\mathrm{d}}^{\prime}\right)}\left[\operatorname{erf}\left(\frac{R_{\mathrm{d}}^{\prime}}{2 \sqrt{D_{\mathrm{Al}}^{\gamma} t}}\right)\right] \frac{\mathrm{d} h_{\alpha-\mathrm{Al}_{2} \mathrm{O}_{3}}}{\mathrm{~d} t}
$$

\subsection{Relationship between $c_{\mathrm{Al}}^{\gamma}(\mathrm{min})$ and ${c^{\prime}}_{\mathrm{Al}}^{\gamma}(\mathrm{min})$}

Comparing Eq (11) and Eq (18), the relationship between $c_{\mathrm{Al}}^{\gamma}(\mathrm{min})$ and $c^{\prime}{ }_{\mathrm{Al}}^{\gamma}(\mathrm{min})$ is

$$
\frac{c_{\mathrm{Al}}^{\gamma}(\min )}{c_{\mathrm{Al}}^{\prime \gamma}(\min )}=\left(\frac{R+R_{\mathrm{d}}^{\prime}}{R-R_{\mathrm{d}}}\right) \frac{\operatorname{erf}\left(\frac{R_{\mathrm{d}}}{2 \sqrt{D_{\mathrm{Al}}^{\gamma} t}}\right)}{\operatorname{erf}\left(\frac{R_{\mathrm{d}}^{\prime}}{2 \sqrt{D_{\mathrm{Al}}^{\gamma} t}}\right)}
$$

Eq (19) describes the fundamental relationship between the minimum $\mathrm{Al}$ concentration in the $\gamma$-phase matrix required to form an exclusive $\alpha-\mathrm{Al}_{2} \mathrm{O}_{3}$ scale on the convex coating surface and that on the concave coating surface.

For a given scale thickness and surface curvature radius, the thickness of the subsurface $\beta$-phase depleted zone $\left(R_{\mathrm{d}}\right.$ and $\left.R_{\mathrm{d}}^{\prime}\right)$ formed during oxidation depends on the ratio of the surface area of the $\alpha-\mathrm{Al}_{2} \mathrm{O}_{3}$ scale to that of the metal subject to $\beta$ phase dissolution. On the convex surface (the solid sphere model in Section 4.1), the metal is covered by the $\alpha-\mathrm{Al}_{2} \mathrm{O}_{3}$ scale. Therefore, the surface area of the $\alpha-\mathrm{Al}_{2} \mathrm{O}_{3}$ scale $\left(4 \pi R^{2}\right)$ is always larger than that of the metal undergoing $\beta$-phase dissolution $\left(4 \pi\left(R-R_{\mathrm{d}}\right)^{2}\right)$. In contrast, on the concave surface (the hollow sphere model in Section 4.2), the $\alpha-\mathrm{Al}_{2} \mathrm{O}_{3}$ scale is covered by the metal. Therefore, the surface area of the $\alpha-\mathrm{Al}_{2} \mathrm{O}_{3}$ scale $\left(4 \pi R^{2}\right)$ is always smaller than that of the metal undergoing $\beta$-phase dissolution $\left(4 \pi\left(R+R^{\prime}{ }_{\mathrm{d}}\right)^{2}\right)$. As a result, for the same thickness of the $\alpha-\mathrm{Al}_{2} \mathrm{O}_{3}$ scale, $R_{\mathrm{d}}$ must be larger than $R_{\mathrm{d}}^{\prime}\left(R_{\mathrm{d}}>R_{\mathrm{d}}^{\prime}\right)$ to compensate for the relatively smaller surface areas of the metal in the convex surface regions. This relationship leads to conclusion 


$$
\frac{\operatorname{erf}\left(\frac{R_{\mathrm{d}}}{2 \sqrt{D_{\mathrm{Al}}^{\gamma} t}}\right)}{\operatorname{erf}\left(\frac{R_{\mathrm{d}}^{\prime}}{2 \sqrt{D_{\mathrm{Al}}^{\gamma} t}}\right)}>1
$$

As $\frac{R+R^{\prime} \mathrm{d}}{R-R_{\mathrm{d}}}>1$, combining Eq (19) and Eq (20) yields

$$
\frac{c_{\mathrm{Al}}^{\gamma}(\min )}{c_{\mathrm{Al}}^{\prime \gamma}(\min )}>1
$$

$\mathrm{Eq}(21)$ predicts that in order to maintain the growth of an exclusive $\alpha-\mathrm{Al}_{2} \mathrm{O}_{3}$ scale, the minimum Al concentration in the $\gamma$-phase matrix in the convex surface region must be higher than that in the $\gamma$-phase matrix in the concave surface region. In other words, as the composition of the $\gamma$-phase matrix in a two-phase $(\beta+\gamma)$ NiCoCrAlY alloy is fixed due to the thermodynamic equilibrium between $\beta$ and $\gamma$, the concave surface is more likely to maintain the growth of an exclusive $\alpha-\mathrm{Al}_{2} \mathrm{O}_{3}$ scale during oxidation. Quantitative STEM-EDS point analysis of the convex and concave regions shows that the $\mathrm{Al}$ concentration in the $\gamma$-phase near the $\alpha-\mathrm{Al}_{2} \mathrm{O}_{3} / \gamma$-phase interface ranges from 2.6 to 4.1 at.\% from place to place after 5 hour oxidation at $1150{ }^{\circ} \mathrm{C}$ (compared to $~ 9.3$ at \% in the $\gamma$-matrix away from the interface). However, no appreciable difference in the Al concentration could be identified between the two types of regions, presumably due to the relatively low Al content in the $\gamma$-phase at the interface, the semi-quantitative nature of the EDS analysis and the intervene of foreign elements pertained to TEM (e.g. Cu from the $\mathrm{Cu}$ grid) and FIB analysis (e.g. Ga implantation). While it has been shown that $\frac{c_{\mathrm{Al}}^{\gamma}(\mathrm{min})}{{c^{\prime}}_{\mathrm{Al}}^{\gamma}(\mathrm{min})}>1, \frac{c_{\mathrm{Al}}^{\gamma}(\mathrm{min})}{{c^{\prime}}_{\mathrm{Al}}^{\gamma}(\mathrm{min})}$ and the effect of $R$ on $\frac{c_{\mathrm{Al}}^{\gamma}(\mathrm{min})}{c_{\mathrm{Al}}^{\gamma}(\mathrm{min})}$ depend on the magnitude of $R$. When $R$ is orders-ofmagnitude larger than $R_{\mathrm{d}}$ and $R^{\prime}{ }_{\mathrm{d}}\left(R \gg R_{\mathrm{d}}\right.$ and $\left.R \gg R^{\prime}{ }_{\mathrm{d}}\right)$, it can be calculated that $\frac{R+R^{\prime}{ }_{\mathrm{d}}}{R-R_{\mathrm{d}}} \approx 1$ and $R_{\mathrm{d}}$ will be extremely close to $R^{\prime}{ }_{\mathrm{d}}\left(R_{\mathrm{d}} \approx R^{\prime}{ }_{\mathrm{d}}\right)$ as the ratio of the surface area of the $\alpha-\mathrm{Al}_{2} \mathrm{O}_{3}$ scale to the surface area of the metal undergoing $\beta$ phase dissolution approximates 1 in both convex and concave surface regions $\left(\frac{4 \pi R^{2}}{4 \pi\left(R-R_{\mathrm{d}}\right)^{2}}=\frac{4 \pi R^{2}}{4 \pi\left(R+R_{\mathrm{d}}^{\prime}\right)^{2}} \approx 1\right)$. Therefore, Eq (19) predicts that $\frac{c_{\mathrm{Al}}^{\gamma}(\mathrm{min})}{{c_{\mathrm{Al}}^{\prime}}_{\mathrm{Al}}^{\gamma}(\mathrm{min})} \approx 1$ and the dependence of $\frac{c_{\mathrm{Al}}^{\gamma}(\mathrm{min})}{{c^{\prime}}_{\mathrm{Al}}^{\gamma}(\mathrm{min})}$ on $R$ becomes negligible. An extreme example of this case 
is that the coating surface becomes perfectly flat $(R \rightarrow \infty)$. In this case, $c_{\mathrm{Al}}^{\gamma}(\mathrm{min})$ (Eq (11)) and $c^{\prime}{ }_{\mathrm{Al}}^{\gamma}(\mathrm{min})(\mathrm{Eq}(18))$ reduce to the same expression: $\lim _{R \rightarrow \infty} c_{\mathrm{Al}}^{\gamma}(\min )=$ $\lim _{R \rightarrow \infty} c^{\prime}{ }_{\mathrm{Al}}^{\gamma}(\min )=\frac{2 V_{\mathrm{m}}^{\gamma}}{V_{\mathrm{m}}^{\alpha-\mathrm{Al}_{2} \mathrm{O}_{3}}} \sqrt{\frac{\pi t}{D_{\mathrm{Al}}^{\gamma}}}\left[\operatorname{erf}\left(\frac{R_{\mathrm{d}}}{2 \sqrt{D_{\mathrm{Al}}^{\gamma} t}}\right)\right] \frac{\mathrm{d} h_{\alpha-\mathrm{Al}_{2} \mathrm{O}_{3}}}{\mathrm{~d} t}$, and, therefore, $\lim _{R \rightarrow \infty} \frac{c_{\mathrm{Al}}^{\gamma}(\mathrm{min})}{c_{\mathrm{Al}}^{\gamma}(\mathrm{min})}=1$. In reality, $R_{\mathrm{d}}$ or $R_{\mathrm{d}}^{\prime}$ generally ranges from microns to tens of microns, depending on oxidation temperatures and time. As a result, any macroscopic surface curvature in structure components is predicted to have negligible effect on selective oxidation of Al on the MCrAlY coatings as $R$ is generally orders-of-magnitude larger than $R_{\mathrm{d}}$ or $R_{\mathrm{d}}^{\prime}$.

When $R$ is close to or of the same magnitude as $R_{\mathrm{d}}$ and $R_{\mathrm{d}}^{\prime}$, however, $\frac{c_{\mathrm{Al}}^{\gamma}(\mathrm{min})}{c^{\prime}{ }_{\mathrm{Al}}^{\gamma}(\min )}$ no longer approximates 1 and quickly increases with decreasing $R$, especially when $R$ approaches to $R_{\mathrm{d}}$ and $R_{\mathrm{d}}^{\prime}$. To illustrate this point in a quantitative approach, Fig. 8 gives an example of the evolution of $\frac{c_{\mathrm{Al}}^{\gamma}(\mathrm{min})}{c_{\mathrm{Al}}^{\prime}(\mathrm{min})}$ as a function of $R(2 \mu \mathrm{m}<R \leq$ $20 \mu \mathrm{m}$ ), where $R_{\mathrm{d}}$ and $R_{\mathrm{d}}^{\prime}$ are assigned as $R_{\mathrm{d}}=R_{\mathrm{d}}^{\prime}=2 \mu \mathrm{m}$. (For simplification purposes, the dependence of $R_{\mathrm{d}}$ and $R^{\prime}{ }_{\mathrm{d}}$ on surface curvature is not considered here and therefore $\operatorname{erf}\left(\frac{R_{\mathrm{d}}}{2 \sqrt{D_{\mathrm{Al}}^{\gamma} t}}\right)$ and $\operatorname{erf}\left(\frac{R^{\prime} \mathrm{d}}{2 \sqrt{D_{\mathrm{Al}}^{\gamma} t}}\right)$ in Eq (19) cancel out. As $\frac{\operatorname{erf}\left(\frac{R_{\mathrm{d}}}{2 \sqrt{D_{\mathrm{Al}}^{\gamma}}}\right)}{\operatorname{erf}\left(\frac{R_{\mathrm{d}}^{\prime}}{2 \sqrt{D_{\mathrm{Al}}^{\gamma}}}\right)}>1$, the plot in Fig. 8 could be treated as the lower bound of $\left.\frac{c_{\mathrm{Al}}^{\gamma}(\mathrm{min})}{c_{\mathrm{Al}}^{\prime}(\mathrm{min})}\right)$. Fig. 8 shows that $\frac{c_{\mathrm{Al}}^{\gamma}(\mathrm{min})}{c_{\mathrm{Al}}^{\prime \gamma}(\mathrm{min})}$ is substantially larger than 1 (e.g. $\frac{c_{\mathrm{Al}}^{\gamma}(\mathrm{min})}{c_{\mathrm{Al}}^{\prime \gamma}(\mathrm{min})}=2$ when $R=6 \mu \mathrm{m}$ ) and increases with decreasing $R$, with this effect being more significant as $R$ approaches $R_{\mathrm{d}}$. For the micro-curvatures present on the HVOF NiCoCrAlY coating surface, the radii of curvatures typically range from a few micrometres to tens of micrometres (e.g. the radii of curvatures shown in Figs. 1 and 3). The significant deviation of $\frac{c_{\mathrm{Al}}^{\gamma}(\mathrm{min})}{c^{\prime}{ }_{\mathrm{Al}}^{\gamma}(\mathrm{min})}$ from 1 when $R$ is in this microscale range explains our experimental observations that the convex regions on the rough HVOF MCrAlY coating surface are prone to spinel formation. 


\section{Conclusions}

The oxidation behaviour of a HVOF NiCoCrAlY coating at $1150{ }^{\circ} \mathrm{C}$ has been studied. It is found that the rough coating surface shows site-specific oxidation: oxidation of the convex surface region is manifested by formation of a TGO with duplex microstructure, consisting of outer $(\mathrm{Ni}, \mathrm{Co})(\mathrm{Cr}, \mathrm{Al})_{2} \mathrm{O}_{4}$ and inner $\alpha-\mathrm{Al}_{2} \mathrm{O}_{3}$; oxidation of the concave surface region, however, is characterised by formation of an exclusive $\alpha$ $\mathrm{Al}_{2} \mathrm{O}_{3}$ scale. Modelling and analysis of $\mathrm{Al}$ diffusion during selective oxidation of $\mathrm{Al}$ in both convex and concave regions predict that any macroscopic surface curvature would play a negligible role in oxidation of MCrAlY coatings. However, when the curvature radius decreases to the microscale, the curvature starts to affect oxidation behaviour of MCrAlY coatings, and this effect becomes more significantly when the curvature radius approaches the thickness of the subsurface $\beta$-depleted zone. The modelling and diffusional analyses explain the difference in oxidation behaviour between the convex regions and the concave regions on the rough surface of the HVOF NiCoCrAlY coating.

\section{Acknowledgements}

The authors would like to acknowledge Nicholas Curry, Nicolaie Markocsan, Per Nylen from Production Technology Centre, University West, Sweden for supply of the samples. The authors are grateful to Mr. Simon McCormack for proof-reading the manuscript.

\section{Data Availability}

The raw/processed data required to reproduce these findings can be shared upon request.

\section{Appendix}

The Maclaurin series of $\operatorname{erf}\left(\frac{R_{\mathrm{d}}}{2 \sqrt{D_{\mathrm{Al}}^{\gamma} t}}\right)$ are expressed as 


$$
\operatorname{erf}\left(\frac{R_{\mathrm{d}}}{2 \sqrt{D_{\mathrm{Al}}^{\gamma} t}}\right)=\frac{2}{\sqrt{\pi}}\left(\frac{R_{\mathrm{d}}}{2 \sqrt{D_{\mathrm{Al}}^{\gamma} t}}-\frac{\left(\frac{R_{\mathrm{d}}}{2 \sqrt{D_{\mathrm{Al}}^{\gamma} t}}\right)^{3}}{3}+\frac{\left(\frac{R_{\mathrm{d}}}{2 \sqrt{D_{\mathrm{Al}}^{\gamma} t}}\right)^{5}}{10}-\frac{\left(\frac{R_{\mathrm{d}}}{2 \sqrt{D_{\mathrm{Al}}^{\gamma} t}}\right)^{7}}{42}+\cdots\right)
$$

As $\frac{R_{\mathrm{d}}}{2 \sqrt{D_{\mathrm{Al}}^{\gamma} t}}>0$, according to Eq (A1)

$$
\operatorname{erf}\left(\frac{R_{\mathrm{d}}}{2 \sqrt{D_{\mathrm{Al}}^{\gamma} t}}\right)<\frac{2}{\sqrt{\pi}} \frac{R_{\mathrm{d}}}{2 \sqrt{D_{\mathrm{Al}}^{\gamma} t}}=\frac{R_{\mathrm{d}}}{\sqrt{\pi D_{\mathrm{Al}}^{\gamma} t}}
$$

Therefore

$$
\frac{1}{\operatorname{erf}\left(\frac{R_{\mathrm{d}}}{2 \sqrt{D_{\mathrm{Al}}^{\gamma} t}}\right) \sqrt{\pi D_{\mathrm{Al}}^{\gamma} t}}-\frac{1}{R}>\frac{1}{\frac{R_{\mathrm{d}}}{\sqrt{\pi D_{\mathrm{Al}}^{\gamma} t}} \sqrt{\pi D_{\mathrm{Al}}^{\gamma} t}}-\frac{1}{R}=\frac{1}{R_{\mathrm{d}}}-\frac{1}{R}>0
$$




\section{References}

1. J.T. Demasimarcin and D.K. Gupta, Protective Coatings in the Gas-Turbine Engine. Surface \& Coatings Technology, 1994. 68: p. 1-9.

2. A.G. Evans, D.R. Mumm, J.W. Hutchinson, G.H. Meier, and F.S. Pettit, Mechanisms controlling the durability of thermal barrier coatings. Progress in Materials Science, 2001. 46(5): p. 505553.

3. G.W. Goward, Progress in coatings for gas turbine airfoils. Surface \& Coatings Technology, 1998. 108(1-3): p. 73-79.

4. N.P. Padture, M. Gell, and E.H. Jordan, Thermal barrier coatings for gas-turbine engine applications. Science, 2002. 296(5566): p. 280-284.

5. D.R. Clarke and C.G. Levi, Materials design for the next generation thermal barrier coatings. Annual Review of Materials Research, 2003. 33: p. 383-417.

6. T.J. Nijdam and W.G. Sloof, Effect of $Y$ distribution on the oxidation kinetics of NiCoCrAlY bond coat alloys. Oxidation of Metals, 2008. 69(1-2): p. 1-12.

7. B.A. Pint, Experimental observations in support of the dynamic-segregation theory to explain the reactive-element effect. Oxidation of Metals, 1996. 45(1-2): p. 1-37.

8. J. Toscano, D. Naumenko, A. Gil, L. Singheiser, and W.J. Quadakkers, Parameters affecting TGO growth rate and the lifetime of TBC systems with MCrA/Y-bondcoats. Materials and Corrosion-Werkstoffe Und Korrosion, 2008. 59(6): p. 501-507.

9. J. Toscano, R. Vassen, A. Gil, M. Subanovic, D. Naumenko, L. Singhelser, and W. Quadakkers, Parameters affecting TGO growth and adherence on MCrAly-bond coats for TBC's. Surface \& Coatings Technology, 2006. 201(7): p. 3906-3910.

10. W. Brandl, H.J. Grabke, D. Toma, and J. Kruger, The oxidation behaviour of sprayed MCrA/Y coatings. Surface \& Coatings Technology, 1996. 86(1-3): p. 41-47.

11. D. Naumenko, B.A. Pint, and W.J. Quadakkers, Current Thoughts on Reactive Element Effects in Alumina-Forming Systems: In Memory of John Stringer. Oxidation of Metals, 2016. 86(1-2): p. 1-43.

12. T.J. Nijdam, L.P.H. Jeurgens, J.H. Chen, and W.G. Sloof, On the microstructure of the initial oxide grown by controlled annealing and oxidation on a NiCoCrA/Y bond coating. Oxidation of Metals, 2005. 64(5-6): p. 355-377.

13. T.J. Nijdam, L.P.H. Jeurgens, and W.G. Sloof, Effect of partial oxygen pressure on the initial stages of high-temperature oxidation of gamma-NiCrAl alloys. Materials at High Temperatures, 2003. 20(3): p. 311-318.

14. W. Brandl, D. Toma, J. Kruger, H.J. Grabke, and G. Matthaus, The oxidation behaviour of HVOF thermal-sprayed MCrA1Y coatings. Surface \& Coatings Technology, 1997. 94-5(1-3): p. 21-26.

15. T.J. Nijdam, C. Kwakernaak, and W.G. Sloof, The effects of alloy microstructure refinement on the short-term thermal oxidation of NiCoCrAlY alloys. Metallurgical and Materials Transactions a-Physical Metallurgy and Materials Science, 2006. 37A(3): p. 683-693. 
16. Y. Chen, X. Zhao, and P. Xiao, Effect of microstructure on early oxidation of MCrA/Y coatings. Acta Materialia, 2018. 159: p. 150-162.

17. W.G. Sloof and T.J. Nijdam, On the high-temperature oxidation of MCrA/Y coatings. International Journal of Materials Research, 2009. 100(10): p. 1318-1330.

18. N. Czech, M. Juez-Lorenzo, V. Kolarik, and W. Stamm, Influence of the surface roughness on the oxide scale formation on MCrA/Y coatings studied in situ by high temperature $X$-ray diffraction. Surface \& Coatings Technology, 1998. 108(1-3): p. 36-42.

19. A. Gil, V. Shemet, R. Vassen, M. Subanovic, J. Toscano, D. Naumenko, L. Singheiser, and W.J. Quadakkers, Effect of surface condition on the oxidation behaviour of MCrAlY coatings. Surface \& Coatings Technology, 2006. 201(7): p. 3824-3828.

20. Y. Chen, X. Zhao, M. Bai, L. Yang, C. Li, L. Wang, J.A. Carr, and P. Xiao, A mechanistic understanding on rumpling of a NiCoCrA1Y bond coat for thermal barrier coating applications. Acta Materialia, 2017. 128: p. 31-42.

21. Y. Chen, X. Zhao, Y. Dang, P. Xiao, N. Curry, N. Markocsan, and P. Nylen, Characterization and understanding of residual stresses in a NiCoCrA/Y bond coat for thermal barrier coating application. Acta Materialia, 2015. 94: p. 1-14.

22. R.M. Langford and A.K. Petford-Long, Preparation of transmission electron microscopy crosssection specimens using focused ion beam milling. Journal of Vacuum Science \& Technology a-Vacuum Surfaces and Films, 2001. 19(5): p. 2186-2193.

23. A. Garner, A. Gholinia, P. Frankel, M. Gass, I. MacLaren, and M. Preuss, The microstructure and microtexture of zirconium oxide films studied by transmission electron backscatter diffraction and automated crystal orientation mapping with transmission electron microscopy. Acta Materialia, 2014. 80: p. 159-171.

24. L. Ajdelsztajn, J.A. Picas, G.E. Kim, F.L. Bastian, J. Schoenung, and V. Provenzano, Oxidation behavior of HVOF sprayed nanocrystalline NiCrAlY powder. Materials Science and Engineering: $A, 2002$. 338(1): p. 33-43.

25. D.J. Jorgensen, A. Suzuki, D.M. Lipkin, and T.M. Pollock, Bond coatings with high rumpling resistance: Design and characterization. Surface and Coatings Technology, 2016. 300: p. 2534.

26. D.J. Jorgensen, A. Suzuki, D.M. Lipkin, and T.M. Pollock, Sulfur and minor element effects on the oxidation of bilayer $\gamma^{\prime}+\beta$ bond coats for thermal barrier coatings on Rrené $N 5$. Superalloys 2016: Proceedings of the 13th intenational symposium of superalloys, 2016: p. 131-140.

27. P. Carter, B. Gleeson, and D.J. Young, Calculation of precipitate dissolution zone kinetics in oxidising binary two-phase alloys. Acta Materialia, 1996. 44(10): p. 4033-4038.

28. J. Crank, The Mathematics of Diffusion. Oxford Univeristy Press, Ely House, London W.1, 1975: p. 89-91.

29. F. Gesmundo, F. Viani, Y. Niu, and D.L. Douglass, The Transition from the Formation of Mixed Scales to the Selective Oxidation of the Most-Reactive Component in the Corrosion of Single and 2-Phase Binary-Alloys. Oxidation of Metals, 1993. 40(3-4): p. 373-393. 
30. T.J. Nijdam, L.P.H. Jeurgens, and W.G. Sloof, Modelling the thermal oxidation of ternary alloys-compositional changes in the alloy and the development of oxide phases. Acta Materialia, 2003. 51(18): p. 5295-5307.

31. T.J. Nijdam, L.P.H. Jeurgens, and W.G. Sloof, Promoting exclusive $\alpha-A / 203$ growth upon hightemperature oxidation of NiCrAl alloys: experiment versus model predictions. Acta Materialia, 2005. 53(6): p. 1643-1653.

32. C. Wagner, Theoretical Analysis of the Diffusion Processes Determining the Oxidation Rate of Alloys. Journal of the Electrochemical Society, 1952. 99(10): p. 369-380. 


\section{Figure Captions}

Fig. 1 Cross-sectional microstructure of the TGOs in two convex surface regions after oxidation at $1150^{\circ} \mathrm{C}$ for 5 hours. Most parts of the TGOs in both regions show duplex microstructure

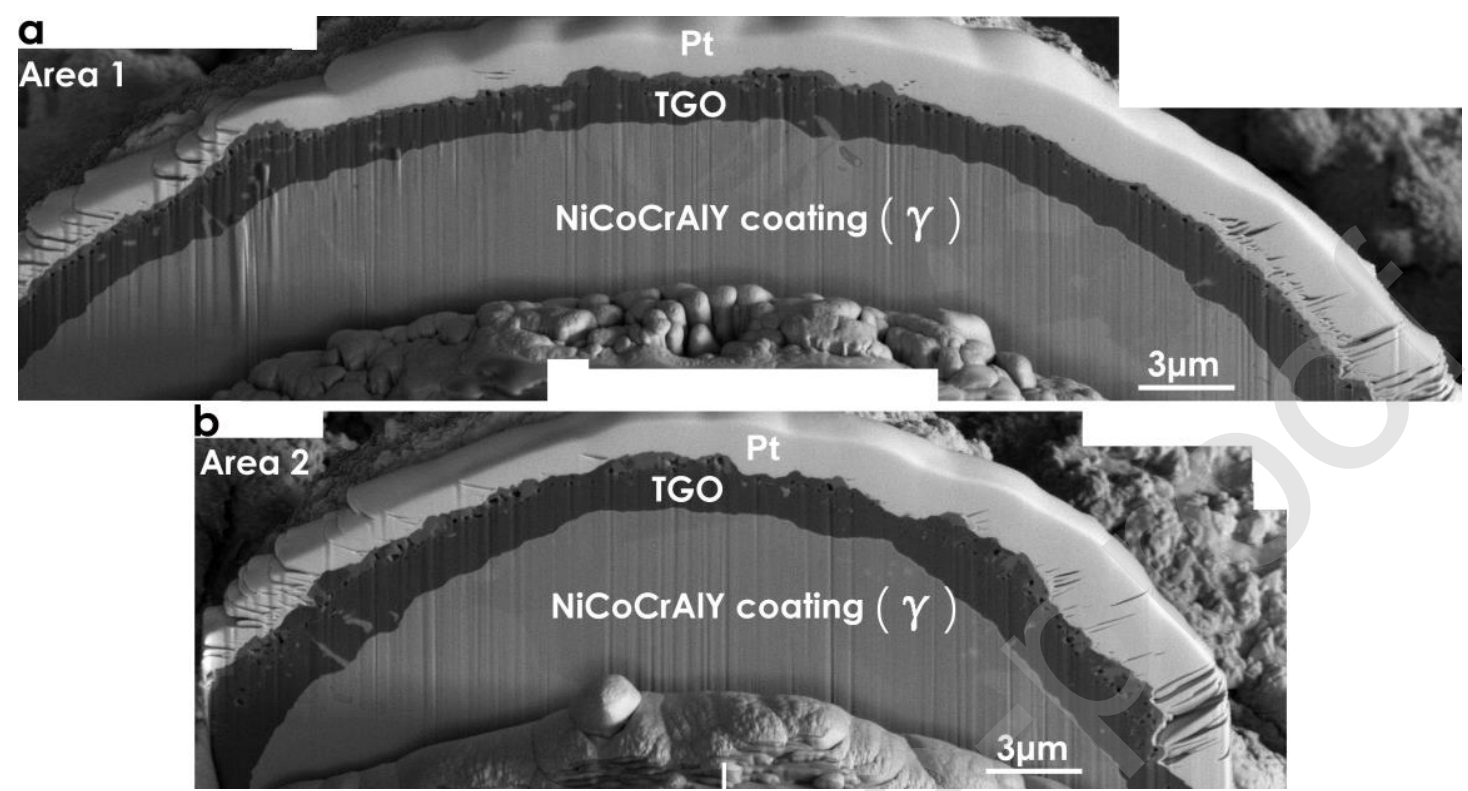


Fig. 2 TEM and TKD analysis of the TGO in a convex surface region after oxidation at $1150{ }^{\circ} \mathrm{C}$ for 5 hours: (a) cross-sectional HAADF-STEM image of the TGO scale and (bg) corresponding $\mathrm{X}$-ray maps of the area in (a); ( $h$ and i) TKD phase contrast maps of the TGO acquired from two different parts of the TGO scale

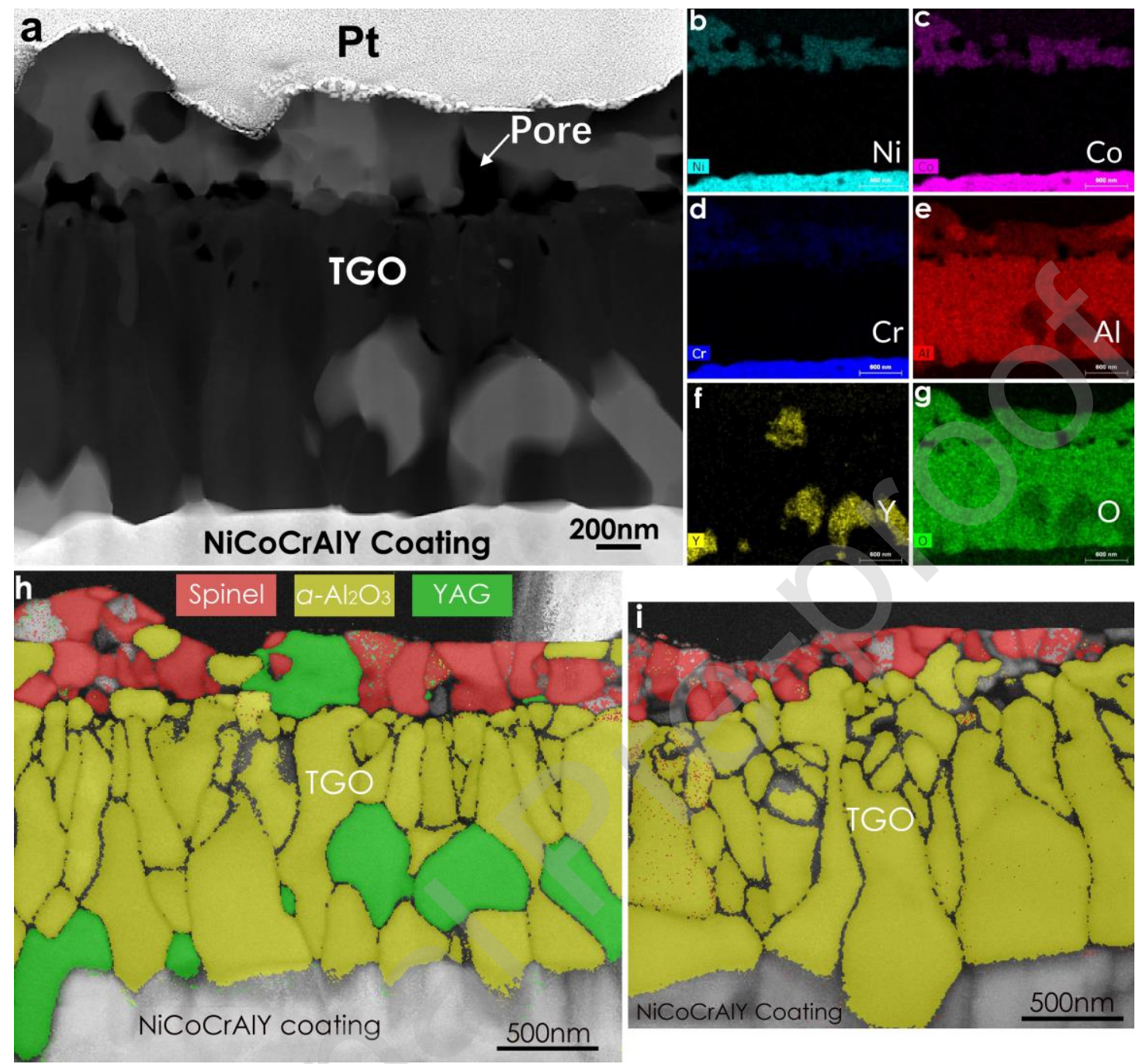

Fig. 3 Cross-sectional microstructure of the TGOs in two concave surface regions after oxidation at $1150^{\circ} \mathrm{C}$ for 5 hours. The TGOs in both regions shows single-layer microstructure 

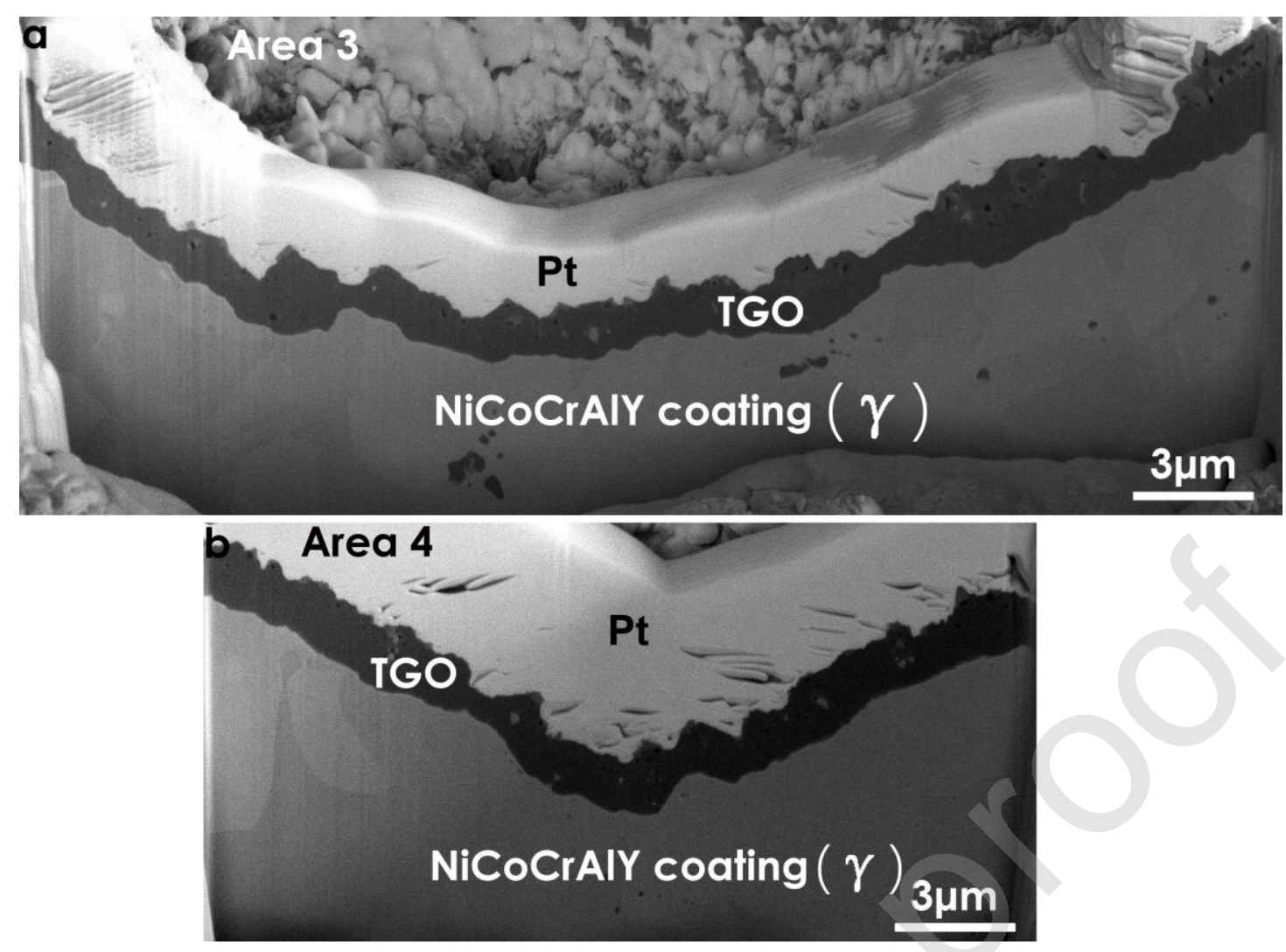

Fig. 4 TEM and TKD analysis of the TGO in a concave surface region after oxidation at $1150{ }^{\circ} \mathrm{C}$ for 5 hours: (a) cross-sectional HAADF-STEM image of the TGO scale and (bg) corresponding $X$-ray maps of the area in (a); ( $h$ and i) TKD phase contrast maps of the TGO acquired from two different parts of the TGO scale 


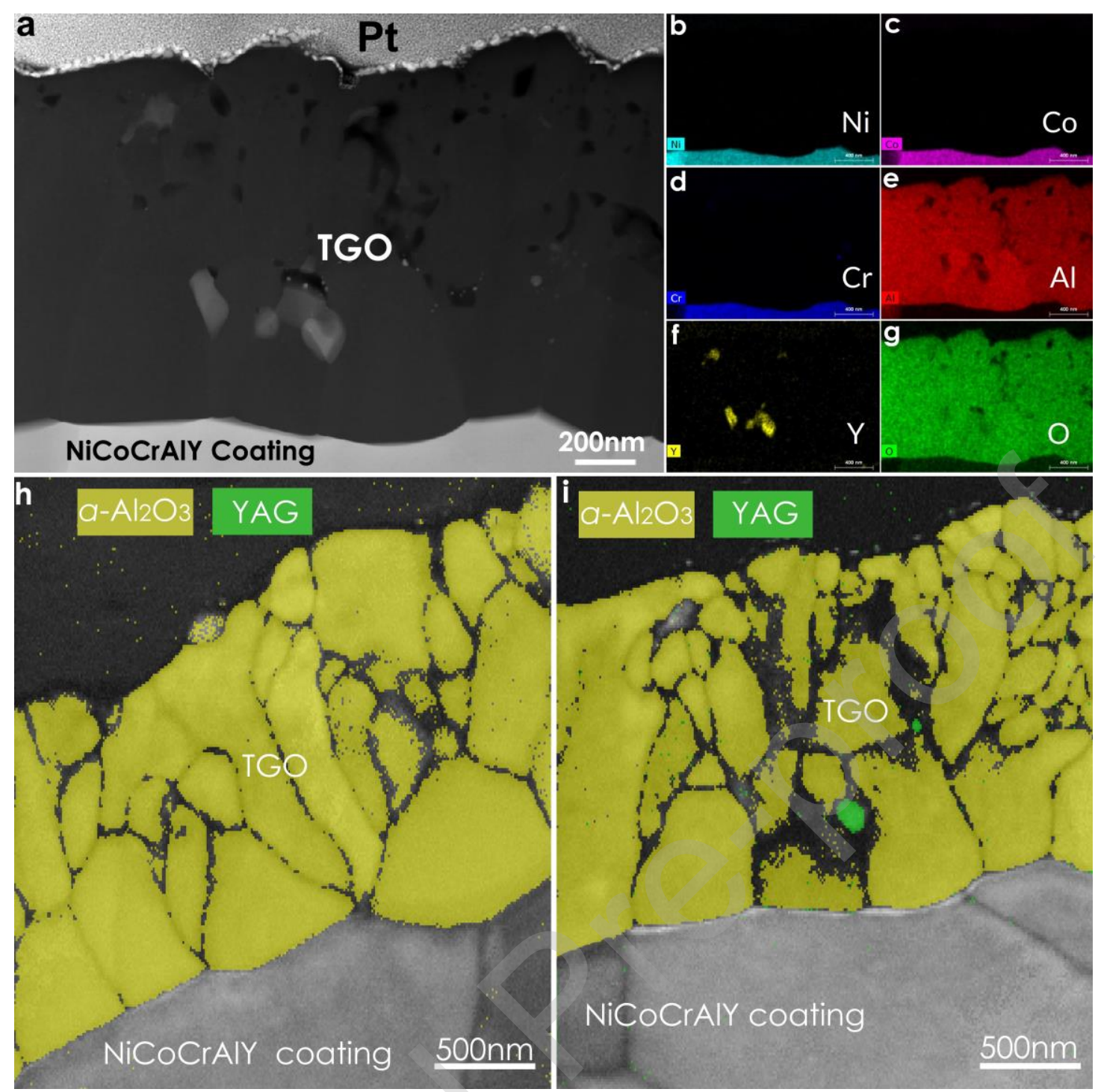

Fig. 5 TEM analysis of the TGO in a convex surface region after oxidation at $1150{ }^{\circ} \mathrm{C}$ for 5 minutes: (a) cross-sectional HAADF-STEM image of the TGO and (b) diffraction pattern of a TGO grain (marked by the white circle in Fig.5a), showing characteristic corundum structure

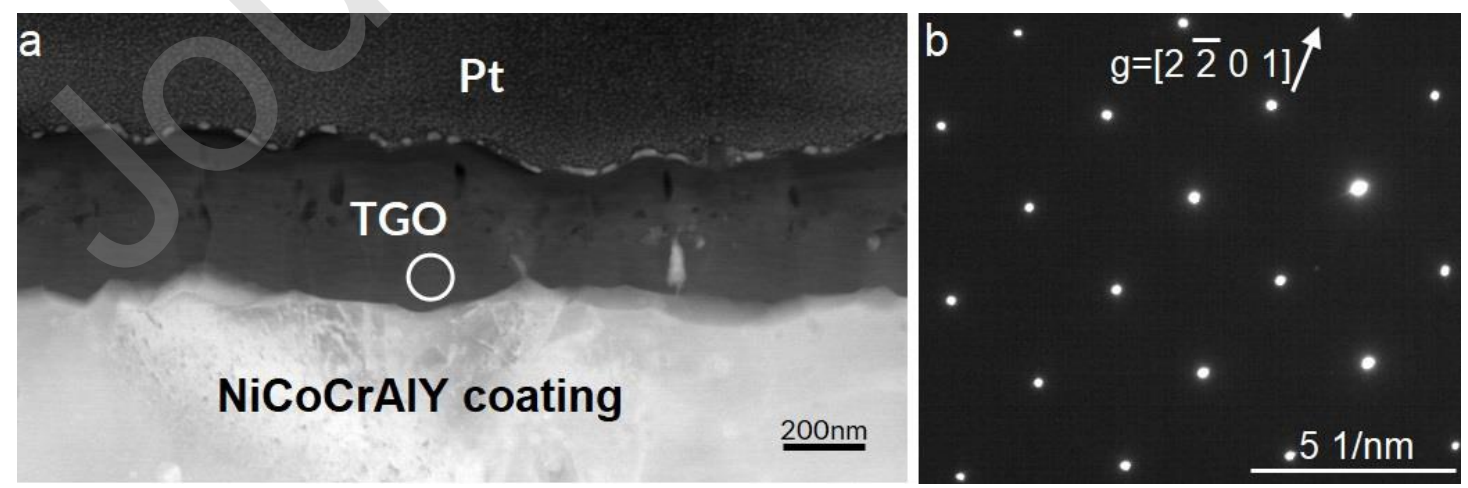


Fig. 6 Schematic illustration of the model representing the selective oxidation of Al in the convex surface region and corresponding boundary conditions
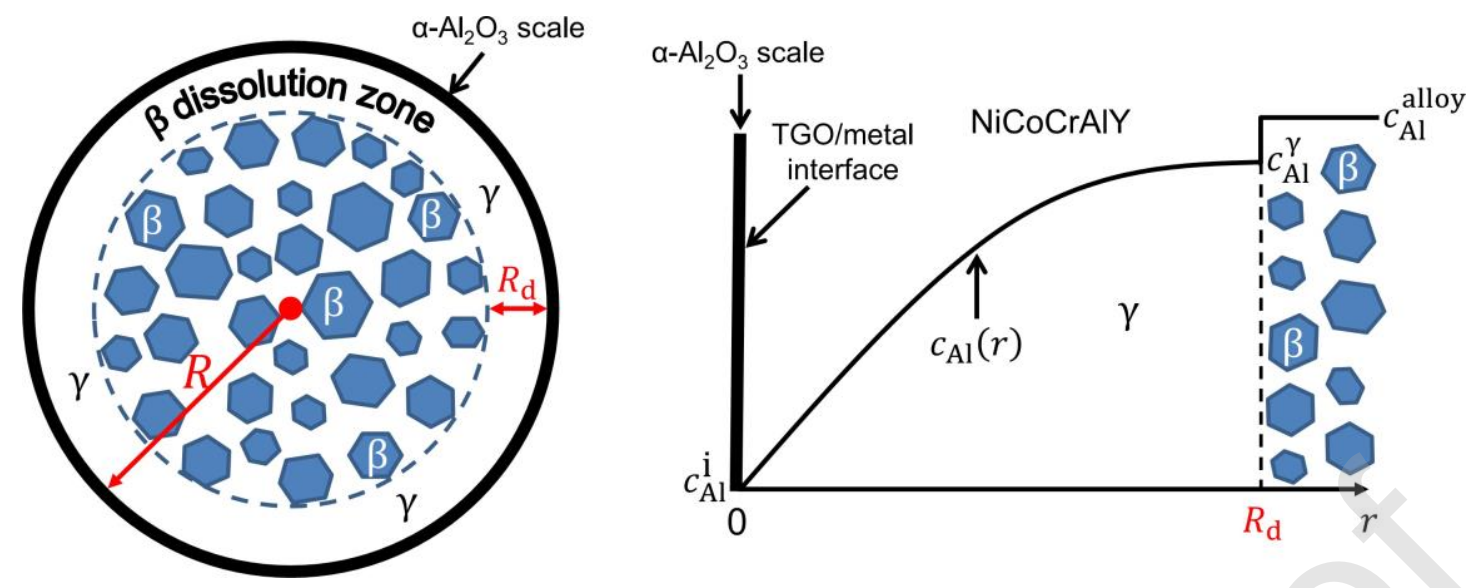

Fig. 7 Schematic illustration of the model representing the selective oxidation of $\mathrm{Al}$ in concave surface regions and corresponding boundary conditions

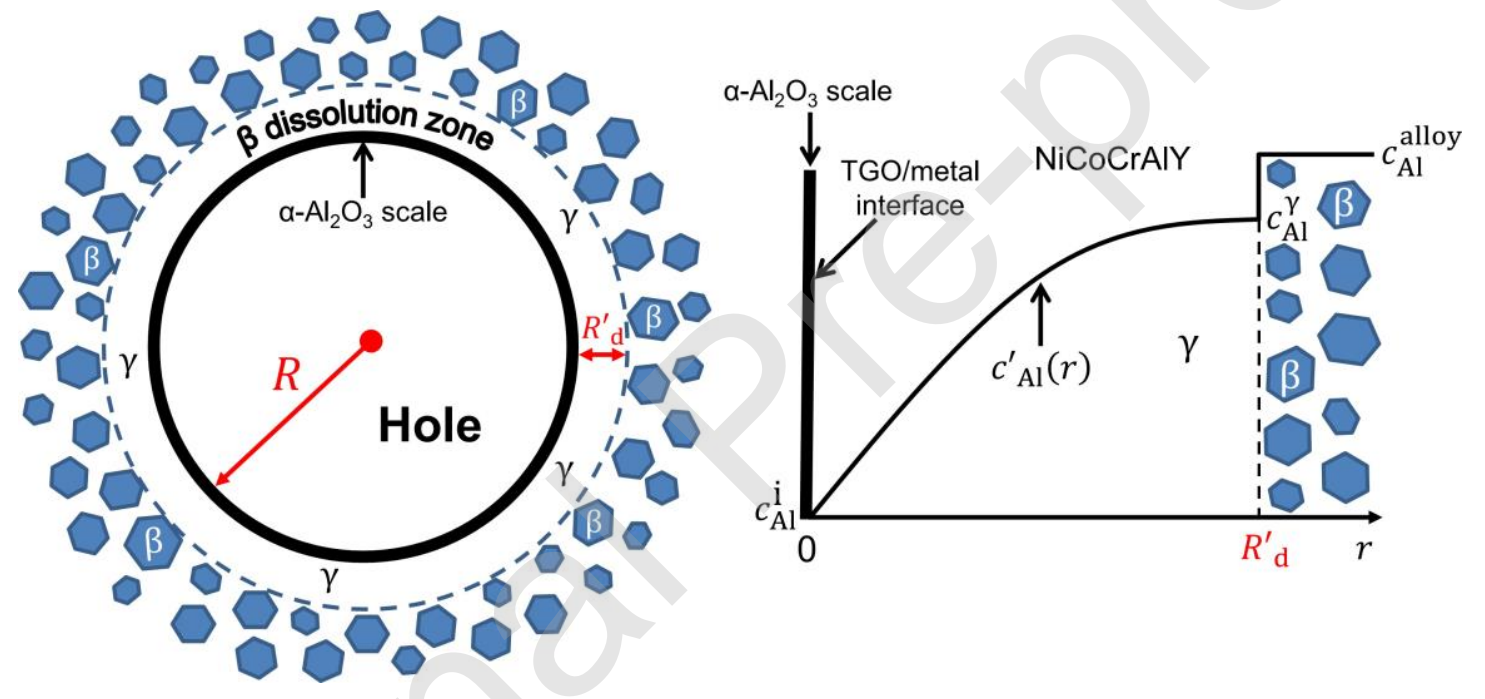

Fig. 8 Evolution of $\frac{c_{\mathrm{Al}}^{\gamma}(\mathrm{min})}{c_{\mathrm{Al}}^{\gamma}(\mathrm{min})}$ as a function of curvature radius for $2 \mu \mathrm{m}<R \leq 20 \mu \mathrm{m}$

$\left(R_{\mathrm{d}}=R_{\mathrm{d}}^{\prime}=2 \mu \mathrm{m}\right)$ 


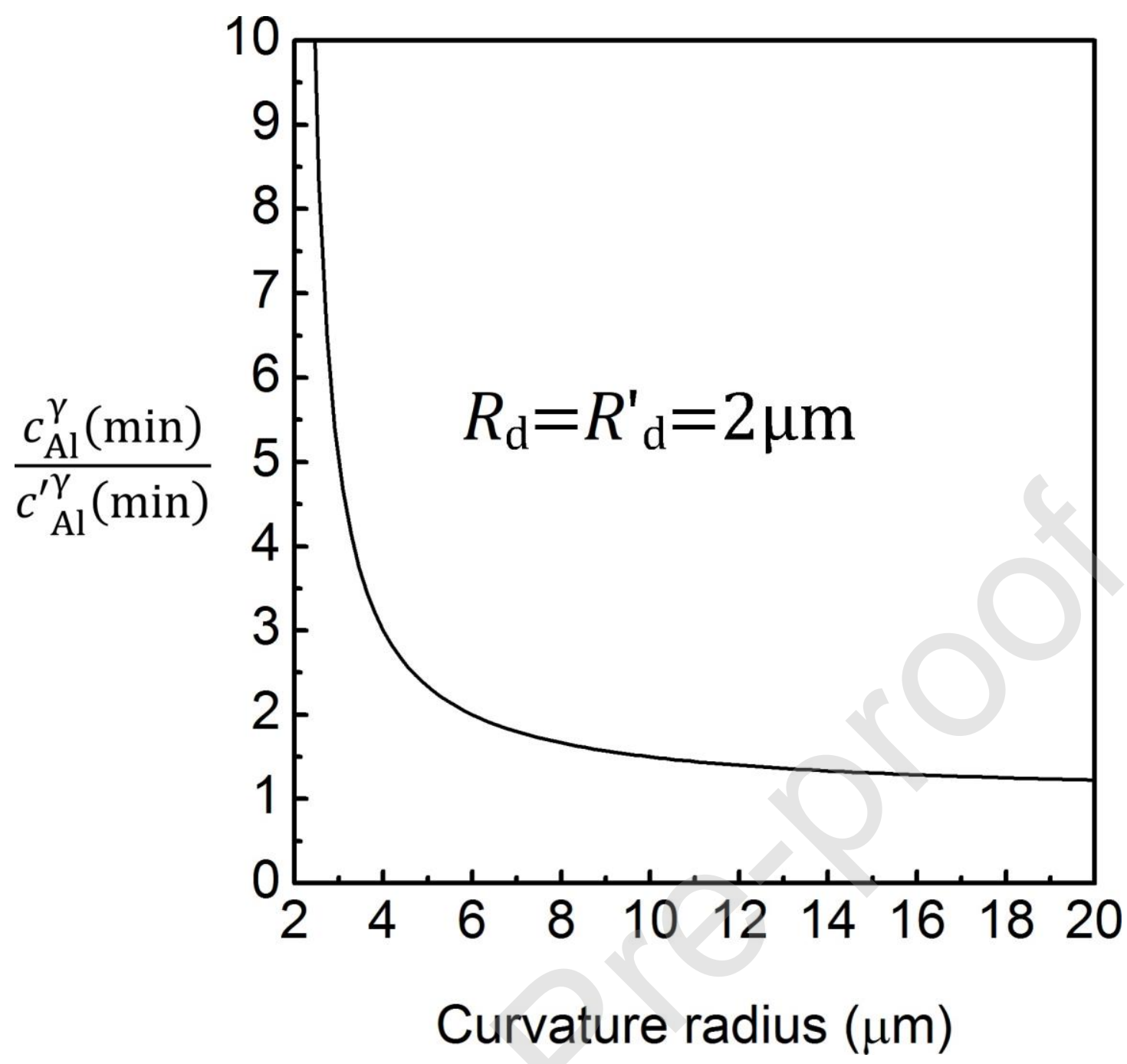

